Research Article

\title{
Prevalence of HPV Genotypes in South Europe: Comparisons between an Italian and a Turkish Unvaccinated Population
}

\author{
Maria Teresa Schettino $\left(\mathbb{D},{ }^{1}\right.$ Pasquale De Franciscis, ${ }^{1}$ Antonio Schiattarella $\left(\mathbb{D},{ }^{1}\right.$ \\ Viviana La Manna, ${ }^{1}$ Alessandra Della Gala, ${ }^{1}$ Francesca Caprio, ${ }^{1}$ Carolina Tammaro, ${ }^{1}$ \\ Franco Pietro Ammaturo, ${ }^{1}$ Tolga Guler ${ }^{1},{ }^{2}$ and Ezgi Hanci Yenigün ${ }^{2}$ \\ ${ }^{1}$ Department of Woman, Child, and General and Specialized Surgery, University of Campania "Luigi Vanvitelli", \\ Largo Madonna Delle Grazie, 1, 80138 Naples, Italy \\ ${ }^{2}$ Department of Obstetrics and Gynecology, Çamlaraltı Mahallesi, Pamukkale University Medical School, Hastane Yolu, \\ 20070 Denizli, Turkey
}

Correspondence should be addressed to Maria Teresa Schettino; mariateresa.sche@libero.it

Received 6 December 2018; Accepted 28 April 2019; Published 19 May 2019

Academic Editor: Tongzhang Zheng

Copyright (C) 2019 Maria Teresa Schettino et al. This is an open access article distributed under the Creative Commons Attribution License, which permits unrestricted use, distribution, and reproduction in any medium, provided the original work is properly cited.

\begin{abstract}
The human papilloma virus (HPV) is a DNA virus associated with benign and malignant lesions of skin and mucous membranes and is the most common sexually transmitted viral infection worldwide. We investigated the prevalence of HPV infection and associated risk factors in Italian and Turkish women population attending the gynecology outpatients clinic in Naples (Italy) and Pamukkale (Turkey). Women were enrolled from the Department of Obstetrics and Gynecology of the University of Campania "Luigi Vanvitelli" in Naples (Italy) and of "Pamukkale University" in Denizli (Turkey) between January 2014 and June 2015. A questionnaire that included sociodemographic and sexual behavior characteristics, questions about HPV awareness, vaccine status, and reasons for not wanting to get vaccinated, and HPV-related knowledge was completed for each participant, and cervical cytology samples were collected. The prevalence of HPV infection was higher in the Italian group (52.6\% vs $32.6 \%$, $p<0.001)$, while the distribution of genotypes is similar $(p=0.325)$. Moreover, the differences in cytological alterations in these patients are significant $(p<0.001)$. The analysis showed a higher prevalence of sexual behavioral characteristics $(p<0.001)$ and better attention to the execution of the screening test in the Italian population $(p<0.001)$. Italian women showed more knowledge and propensity to vaccination compared to Turkish women $(p<0.001)$. Our data highlighted three relevant aspects: the different prevalence of cytological abnormalities, the different distribution of risk factors and, above all, the different attitude of women towards the primary prevention of cervical cancer between an Italian and a Turkish population group.
\end{abstract}

\section{Introduction}

Human papilloma virus (HPV) is a double-stranded DNA virus belonging to the Papillomaviridae family and is the most common sexually transmitted viral infection worldwide, and it is associated with the occurrence of condylomas and a variety of cancers in both women and men [1,2]. The HPV-DNA contains sequences that encode E6 and E7, two proteins with oncogenic capacity, that can disrupt the function of two tumor suppressor genes, p53 and pRb, respectively, causing different cellular pathways alterations and uncontrolled cell growth [3]. There are more than $100 \mathrm{HPV}$ types, and the outcome of HPV infection depends on the specific HPV type/s present and can be from asymptomatic infection until high squamous cell malignancies [4]. Low-risk HPV types, such as types 6 and 11, are associated with anogenital warts and mild dysplasia, while high-risk types, such as 16 and 18, are associated with highgrade dysplasia and cancers of the cervix, vulva, vagina, urethra, penis, anus, and oropharynx. Moreover, cervical cancer is the fourth most common type of cancer for women 
worldwide and the second most common female cancer in women between 15 and 44 years in Europe [5]. Literature evidences that the protection offered by HPV vaccines is enduring and extended vaccination could deliver substantial health economic benefits $[6,7]$. Otherwise, monitoring the impact of HPV vaccine effectiveness, in Europe, is challenging because of the variety of factors that need consideration, like the different policies (targeting both sexes and time of vaccination), health system outcomes, and biologic outcomes as infection, risk factors, and sexual behavioral characteristics [8-10]. Vaccination in Italy is recommended and offered to adolescents of both sexes, preferably around 12 years of age: from 9 to 14 years, a bivalent or quadrivalent vaccine was administered in two doses at 0 and 6 months. In later ages, vaccines were administered in three doses at 0,1 , and 6 (bivalent) or 0,2 , and 6 months (quadrivalent vaccine) $[11,12]$. The bivalent Cervarix ${ }^{\circledR}$ HPV vaccine (GSK Aspen) targets HPV types 16 and 18, while quadrivalent Gardasil ${ }^{\circledR} \mathrm{HPV}$ vaccine (MSD) targets HPV types 6, 11, 16, and 18. A new vaccine will expand coverage against five more oncogenic types (HPV 31, 33, 45, 52, and 58) in addition to the four original types included in quadrivalent vaccine. In Campania, in the south of Italy, the pap test still largely appears as the only screening resource for cervical cancer while the vaccination coverage showed the difficulty of reaching high levels $[13,14]$. In Turkey, instead, the National Standards of Cervical Cancer Screening recommends having a smear at least once between the ages of 35 and 40 years with repeat screening every five years, until the age of 65, with two consecutive negative tests. Patients with a cytological or positive anomaly to HPV types $16 / 18$ undergo colposcopy. However, within the same Turkish territory, this screening programme has a highly inhomogeneous distribution because of different and conflicting socioeconomic realities between the territories of western and eastern Turkey. Otherwise, vaccination is only available through private demand $[15,16]$. In order to optimize the vaccination programs, it is important to support the beneficial effects of the vaccine and spread awareness about high-risk sexual behavior through the media $[17,18]$. Our study aims to compare the Turkish and the Italian population in order to assess the prevalence of HPV infection and the distribution of cytological lesions and the prevalence of sexual behavioral characteristics and environmental risks associated with HPV infection.

\section{Materials and Methods}

We performed a retrospective cohort study of outpatient women who came for gynecological examination, between January 2014 and June 2015, to two referral centers: the Department of Obstetrics and Gynecology of the University of Campania "Luigi Vanvitelli" in Naples (Italy) and of "Pamukkale University" in Denizli (Turkey). The Local Institutional Review Board approved the study. All participants before enrollment signed a full written consent form. The study was conducted in accordance with the principles of Helsinki Declaration. Inclusion criteria were being 25 years of age or older and active sexual history. Patients with autoimmune diseases or any diseases involving the immune system, with HIV infection, previously vaccinated against $\mathrm{HPV}$, with a presumed or confirmed pregnancy, with a diagnosis of any malignancies or with a history of chemotherapy or radiotherapy, and with a history of total uterine or cervical resection, were excluded from the study. The study was performed according to the STROBE (strengthening the reporting of the observational studies in epidemiology) guidelines [19]. Cervical cytology samples were collected, strictly during the nonmenstrual period, by three gynecologists using the Abbott cervi-collect specimen collection kit (Abbott) and transported in ThinPrep ${ }^{\circledR}$ PreservCyt ${ }^{\circledR}$ Solution (HOLOGIC ${ }^{\mathrm{TM}}$ ). These specimens were stored at 15 to $20^{\circ} \mathrm{C}$ and transported to the laboratory within 24 hours of collection. $15 \mathrm{ml}$ of cervical samples was centrifuged at $2000 \mathrm{rpm}$ for 15 minutes at $4^{\circ} \mathrm{C}$ for cervical cells concentration. Cell pellet was suspended in $2.5 \mathrm{ml}$ of PBS, and 5 aliquots of $500 \mu \mathrm{l}$ for each sample were obtained. One aliquot was used for DNA extraction. DNA extraction from a $500 \mu \mathrm{l}$ cell pellet aliquot of the cervical sample was carried out using the linear array test (Roche Molecular Diagnostics, Milan, Italy), a qualitative in vitro test for the detection of HPV in clinical specimens. The test utilizes amplification of target DNA by polymerase chain reaction and nucleic acid hybridization and detects 37 anogenital HPV-DNA genotypes $(6,11,16,18,26,31,33,35,39,40,42$, $45,51,52,53,54,55,56,58,59,61,62,64,66,67,68,69,70$, 71, 72, 73 (MM9), 81, 82 (MM4), 83 (MM7), 84 (MM8), IS39, and CP6108) in cervical cells collected in PreservCyt solution. Three experienced cytology experts performed cervical liquid-based cytology tests and formulated cytological reports according to the Bethesda System [20]. PreservCyt specimens were stored at 15 to $20^{\circ} \mathrm{C}$ for as long as five weeks, in case the sample had to be retested. Women positive for high-risk HPV were recalled and underwent a colposcopic examination and, if there were an evident lesion, also a targeted biopsy. A targeted biopsy was performed to all those HPV-positive patients with cytological lesions. The cytohistological and viral information obtained was inserted in a specific database. All charts recorded in the database were reviewed carefully by two authors. Data were anonymized before analysis. All patients completed a questionnaire that included sociodemographic and lifestyle information, questions about HPV awareness, vaccine status, and reasons for not wanting to get vaccinated and HPV-related knowledge in order to determine personal risks factors that could increase the susceptibility to HPV. Data were shown as means \pm standard deviation (SD) for continuous variables or as number (percentage). Comparisons between the two groups were assessed with Student's $t$-test. Comparison groups were assessed with Pearson's chi-square test and Fisher's exact test for categorical variables and Student's $t$-test for continuous variables. A $p$-value $<0.05$ was considered statistically significant. Statistical analysis was made using SPSS for Windows (version 15.0, SPSS, Chicago, IL).

\section{Results}

Seven hundred three women were recruited for the study and 570 participants (aged between 25 and 65 years, median 
$35.6 \pm 4.5$ years) were enrolled. One hundred thirty-three patients were excluded according to the exclusion criteria as shown in Figure 1.

Patients were divided into two groups according to the country of the enrollment: 300 patients in the Italian group (group A) and 270 patients in the Turkish group (group B). The comparison between the two groups showed that the prevalence of HPV infection was higher in the Italian group than in the Turkey one: $52.6 \%(n=158)$ vs $32.6 \%(n=88)$, $p<0.05$. The distribution of genotypes is similar in the groups of positive HPV patients $(p=0.325)$ as shown in Table 1 .

Table 2 showed a higher incidence of cytological alterations in group A: the percentage of high-grade lesions $(\mathrm{H}-$ SIL) and low-grade lesions (L-SIL), in fact, is higher in group A $(20.3 \%$ vs $8.0 \%, p<0.05$, and $23.4 \%$ vs $6.8 \%, p<0.05$, respectively). Otherwise, group $B$ showed a greater frequency of atypical squamous cells of undeterminated significance (ASCUS) $(43.2 \%$ vs $25.3 \%, p<0.05)$.

Women positive for high-risk HPV were recalled and underwent a colposcopic examination and, if there were an evident lesion, also a targeted biopsy. The results of the biopsies showed a higher incidence of CIN I and CIN II-III in the Italian group and also if not significant $(p=1.000$ and $p=0.688$, respectively) as shown in Table 3 .

The questionnaire revealed a greater prevalence of risk factors associated with HPV infection in the Italian group, in particular for low-age first sexual intercourse and the high number of partners in the last three months $(p<0.05)$. Other risk factors like smoking, use of oral contraceptives, and sexually transmitted infections were more prevalent in the Italian group but not statistically significant. Moreover, the Italian group showed greater attention to the execution of the pap test as a screening test $(p<0.05)$, probably related to a higher degree of education $(p<0.05)$. The distribution of risk factors is shown in Table 4 .

The two groups showed an overlapping level of knowledge about the screening for cervix cancer, but, surprisingly, group A showed more knowledge about the vaccine and a higher propensity to use it compared to the Turkish group $(p<0.05)$. Moreover, the Turkish group showed a lower willingness to have their children vaccinated against HPV $(p<0.05)$. Data are shown in Table 5.

\section{Discussion}

HPV is the most common viral infection of the reproductive tract, and most people are infected with HPV shortly after the onset of sexual activity [21, 22]. Although most precancerous lesions resolve spontaneously, there is a risk for all women that HPV infection may become chronic and precancerous lesions progressing to invasive cervical cancer in 15 to 20 years $[3,23]$. In the era of the vaccine approach as a preventive strategy against cancer associated with HPV infection, epidemiological studies about the distribution of high-risk HPV in different geographical regions are a key tool for several objectives. We need to identify specific risk factors that can be removed with targeted prevention campaigns, to adopt vaccination strategies tailored to every single national reality, to develop vaccines that include

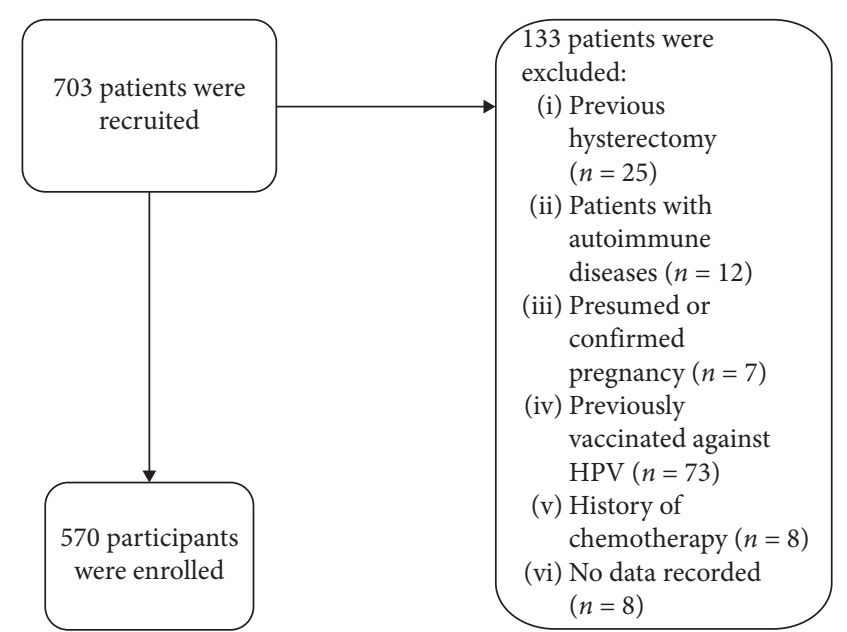

FIGURE 1: Strengthening the reporting of observational studies in epidemiology (STROBE) statement.

TABle 1: Distribution of genotyping in HPV-positive patients.

\begin{tabular}{lccc}
\hline & $\begin{array}{c}\text { Group A (Italian) } \\
(n=158)\end{array}$ & $\begin{array}{c}\text { Group B (Turkish) } \\
(n=88)\end{array}$ & $\begin{array}{c}p \\
\text { value }\end{array}$ \\
\hline Low & $41(26.0 \%)$ & $23(26.2 \%)$ & 1.000 \\
Intermediate & $12(7.5 \%)$ & $5(5.6 \%)$ & 0.793 \\
High & $105(66.5 \%)$ & $60(68.2 \%)$ & 0.887 \\
\hline
\end{tabular}

TABLE 2: Incidence of cytological alterations in HPV-positive patients.

\begin{tabular}{lccc}
\hline & $\begin{array}{c}\text { Group A (Italian) } \\
(n=158)\end{array}$ & $\begin{array}{c}\text { Group B (Turkish) } \\
(n=88)\end{array}$ & $\begin{array}{c}p \\
\text { value }\end{array}$ \\
\hline Negative & $49(31 \%)$ & $37(42 \%)$ & 0.094 \\
ASCUS & $40(25.3 \%)$ & $38(43.2 \%)$ & 0.004 \\
L-SIL & $37(23.4 \%)$ & $6(6.8 \%)$ & 0.0008 \\
H-SIL & $32(20.3 \%)$ & $7(8.0 \%)$ & 0.0110 \\
\hline
\end{tabular}

ASCUS: atypical squamous cells of undeterminated significance; L-SIL: low-grade squamous intraepithelial lesions; H-SIL: high-grade squamous intraepithelial lesions.

Table 3: Outcome of biopsies.

\begin{tabular}{lccc}
\hline & $\begin{array}{c}\text { Group A (Italian) } \\
(n=83)\end{array}$ & $\begin{array}{c}\text { Group B (Turkish) } \\
(n=13)\end{array}$ & $\begin{array}{c}p \\
\text { value }\end{array}$ \\
\hline Negative & $56(67.5 \%)$ & $11(84.6 \%)$ & 0.332 \\
CIN-1 & $12(14.5 \%)$ & $1(7.7 \%)$ & 1.000 \\
CIN-2/3 & $15(18 \%)$ & $1(7.7 \%)$ & 0.688 \\
\hline
\end{tabular}

CIN: cervical intraepithelial neoplasia.

prevalent high-risk HPV in different populations, and to identify high-risk genotypes poorly represented in the general population, such as immigrants [24]. Otherwise, our study has some limitations since its results cannot be generalized as it was conducted in two hospitals from two different countries. Moreover, the results of the study are limited to the period when data were collected. However, data showed a similar distribution between the Italian and Turkish groups about the different HPV genotypes but a 
TABLE 4: Distribution of risk factors.

\begin{tabular}{|c|c|c|c|}
\hline & $\begin{array}{c}\text { Group A } \\
\text { (Italian) } \\
(n=158) \\
\end{array}$ & $\begin{array}{c}\text { Group B } \\
\text { (Turkish) } \\
(n=88)\end{array}$ & $\begin{array}{c}p \\
\text { value }\end{array}$ \\
\hline Age $($ mean $\pm S D)$ & $32.5 \pm 11.4$ & $30.6 \pm 9.6$ & 0.187 \\
\hline \multicolumn{4}{|l|}{ Education } \\
\hline Low levels of education & $23(14.6 \%)$ & $28(31.8 \%)$ & \multirow[t]{3}{*}{$<0.001$} \\
\hline $\begin{array}{l}\text { Upper secondary } \\
\text { education }\end{array}$ & $108(68.4 \%)$ & $47(53.4 \%)$ & \\
\hline Graduate education & $27(17.0 \%)$ & $13(14.8 \%)$ & \\
\hline
\end{tabular}

\begin{tabular}{lccc}
\hline $\begin{array}{l}\text { Marital status } \\
\text { Married or married-like }\end{array}$ & $118(74.7 \%)$ & $48(54.5 \%)$ & $<0.001$ \\
situation & $35(22.1 \%)$ & $38(43.2 \%)$ & \\
Never married & $5(3.2 \%)$ & $2(2.3 \%)$ & \\
Divorced & 0 & 0 & \\
Widow & &
\end{tabular}

\begin{tabular}{lccc}
\hline Smoke & & & \\
Ever smoked & $82(52.0 \%)$ & $35(40.0 \%)$ & 0.067 \\
Current or ex-smokers & $76(48.0 \%)$ & $53(60.0 \%)$ & \\
\hline Number of pregnancies & & & \\
None & $85(53.8 \%)$ & $40(45.4 \%)$ & 0.315 \\
From 1 to 3 & $66(41.8 \%)$ & $41(46.6 \%)$ & \\
More than 3 & $7(4.4 \%)$ & $7(8.0 \%)$ &
\end{tabular}

Combined oral

contraceptive

$\begin{array}{llll}\text { User } & 80(50.6 \%) & 35(39.8 \%) & 0.101\end{array}$

\begin{tabular}{|c|c|c|}
\hline Not & $78(494 \%)$ & $53(60.0 \%)$ \\
\hline
\end{tabular}

intercourse (mean \pm SD) $\quad 19.8 \pm 3.4 \quad 26.4 \pm 5.3 \quad<0.001$

Number of partners (in

the last three months)

$\begin{array}{lccc}\text { Only } 1 & 68(43.3 \%) & 68(77.0 \%) & <0.001 \\ \text { From } 2 \text { to } 3 & 60(37.8 \%) & 13(15.2 \%) & \\ \text { From } 4 \text { to } 9 & 30(18.9 \%) & 7(7.8 \%) & \end{array}$

Condom

Never used during their

sex life $45(28.5 \%) \quad 28(31.9 \%) \quad 0.582$

Usually used during

their sex life

$113(71.5 \%) \quad 60(68.1 \%)$

History of sexually

transmitted infection

$\begin{array}{lccc}\text { Yes } & 27(17.1 \%) & 10(11.4 \%) & 0.228 \\ \text { No } & 131(82.9 \%) & 78(88.6 \%) & \end{array}$

Pap test done in the last

3 years

$\begin{array}{llll}\text { Yes } & 92(58.2 \%) & 29(33.0 \%) & <0.001 \\ \text { No } & 66(41.8 \%) & 59(67.0 \%) & \end{array}$

higher incidence of high-grade cytological lesions in the Italian group. This result could be related to some sexual risk factors that were more frequent in the Italian population, and this point needs to be further studied. As regards the data emerging from the questionnaires, one of the greatest risk factors is represented by smoking due to its potential immunosuppressive effect which can increase the persistence of HPV infection. Literature indicates that the increased risk of cervical cancer is about 2-fold higher among woman smokers compared to nonsmokers, even after appropriate adjustments for sexual habits $[25,26]$. However, use of oral contraceptives could promote cervical ectropion
TABLE 5: Knowledge and approach of patients in comparison of $\mathrm{HPV}$ and vaccine.

\begin{tabular}{ccc}
\hline $\begin{array}{c}\text { Group A } \\
\text { (Italian) } \\
(n=158)\end{array}$ & $\begin{array}{c}\text { Group B } \\
(\text { Turkish }) \\
(n=88)\end{array}$ & $\begin{array}{c}p \\
\text { value }\end{array}$ \\
\hline
\end{tabular}

\begin{tabular}{lccc}
\hline $\begin{array}{l}\text { Knowledge of the motivation of } \\
\text { the screening with the pap test }\end{array}$ & & & \\
Yes & 111 & $53(60.2 \%)$ & 0.109 \\
No & $47(29.8 \%)$ & $35(39.8 \%)$ & \\
\hline HPV knowledge & & & \\
Yes & $90(57.0 \%)$ & $28(31.9 \%)$ & $<0.001$ \\
No & $68(43.0 \%)$ & $60(68.1 \%)$ & \\
\hline
\end{tabular}

Knowledge of the anti-HPV

vaccine

$\begin{array}{llll}\text { Yes } & 71(44.9 \%) & 18(20.4 \%) & <0.001\end{array}$

No

$87(55.1 \%) \quad 70(79.6 \%)$

Knowledge about how

the HPV vaccine works

Yes

No

$41(26.0 \%) \quad 18(20.4 \%) \quad 0.333$

117
$(74.0 \%)$

Positive propensity for

personal use of the vaccine

\begin{tabular}{|c|c|c|c|}
\hline Yes & $\begin{array}{c}111 \\
(70.2 \%)\end{array}$ & $37(42.0 \%)$ & $<0.001$ \\
\hline No & $47(29.8 \%)$ & $51(58.0 \%)$ & \\
\hline \multicolumn{4}{|c|}{$\begin{array}{l}\text { Positive propensity for the } \\
\text { vaccine for children }\end{array}$} \\
\hline Yes & $\begin{array}{c}111 \\
(70.2 \%)\end{array}$ & $37(42.0 \%)$ & $<0.001$ \\
\hline No & $47(29.8 \%)$ & $51(58.0 \%)$ & \\
\hline
\end{tabular}

that facilitates the exposure of the squamocolumnar junction to potential carcinogens and increased risk of vulvovaginitis and predisposition to dysplasia [27-29]. Alternatively, the use of estrogen and progesterone could maintain infection by increasing cell proliferation and papilloma virus transcription [30, 31]. An innovative aspect of our work is related to recent literature evidence suggesting a role for eating habits and the nutritional status of patients in the progression of cervical carcinoma. In particular, it has been suggested a protective role of folate and vitamins $\mathrm{C}$ and $\mathrm{E}$ against cervical cancer: they may increase the immune response of the cervix mucosa to HPV infection or act as blockers of free radicals and oxidants that can cause damage to DNA, proteins, and lipids and inhibit the formation of DNA adducts, produced by tobacco smoke [32-34]. In this regard, it was interesting to observe the different eating habits in the two groups. In the typical diet of the Turkish population, there is a high prevalence of daily consumption of raw vegetables and fruit, rich in vitamins and antioxidants: these factors have been called into question with a protective role against the risk of cervical cancer [35, 36]. Moreover, our data showed a better knowledge about HPV of Italian patients compared to Turkish women and higher willingness to have their children vaccinated against HPV. These data are in agreement with two previous studies that revealed that Turkish women have limited awareness and knowledge about the HPV vaccine and a greater need for 
knowledge $[37,38]$. Furthermore, they are likely to reflect the different territorial realities. In Italy, instead, information campaigns for HPV are widespread and the vaccine has been institutionalized since 2007/2008 for all girls from 12 years of age; in 2014, a national coverage of $71 \%$ was achieved, with profound differences between the different regional realities ranging between $27 \%$ and $86 \%$. In particular, in Campania, the vaccination program reached coverage of $56.1 \%$ for a completing vaccination (3 doses) for the 1997 birth cohort on 31/12/2017 [14, 39]. The Italian National Plan of Vaccination Prevention 2017-2019 established the achievement, in girls in the twelfth year of life, of vaccination coverage for a complete cycle of anti-HPV $\geq 95 \%$; in 2017 , the introduction of anti-HPV vaccination for 11-year-old males with the initiation of an active call for the 2006 cohort; and in 2018, the completion of the antiHPV vaccination in favor of 11-year-old males for the cohort of those born in 2007, with the completion of the recovery of the cohort of those born in 2006 if not achieved in 2017. It should be noted that, in Italy also, the adhesion to screening programs for cervical cancer is very low, with a national average of about $40 \%$ [40-42]. Otherwise, in Turkey, there is no similar national vaccine prevention plan for HPV and there is also a lack of a campaign to spread awareness about HPV. Moreover, vaccination is only available through private demand. On the other hand, the level of risk for HPV infection and the prevalence of the infection are much lower than that of Italian women [43, 44]. In order to assess an effective cervical cancer prevention program, it is necessary to implement both strategies: to achieve greater adhesion of the pediatric and adolescent population to the vaccination program, and therefore work to improve communication aspects to families through complete, clear, and transparent information. From this point of view, it would be advisable to make communication more effective by involving other professionals in support of public health facilities such as pediatricians, consultants, general practitioners, gynecologists, and referents of screening programs. Moreover, it should be highlighted the importance to increase adherence to cervical screening programs through the pap smear, which remains an indispensable tool for the cohort of women who got vaccinated.

\section{Conclusions}

Our data underline three relevant epidemiological aspects that could, if confirmed by larger case studies, address the prevention strategies of the cervical cancer and personalize them on the needs of specific realities: the different prevalence of cytological abnormalities, the different distribution of risk factors among the populations under examination and, above all, the different attitude of women towards the primary prevention of cervical cancer. While in Turkey, it is a priority to create a national database of screening and prevention of HPV that is currently lacking and to launch an information campaign and a vaccination plan. In Italy, instead, the level of knowledge and perception regarding the cervical disease, HPV vaccination, and screening for cervical cancer is still not satisfied, and other studies are necessary to give insight regarding knowledge, perception, and acceptance about the HPV vaccine.

\section{Data Availability}

The data used to support the findings of this study are available from the corresponding author upon request.

\section{Ethical Approval}

Ethical clearance was obtained from the Department of Obstetrics and Gynecology of the University of Campania "Luigi Vanvitelli" in Naples (Italy) and of "Pamukkale University" in Denizli (Turkey).

\section{Conflicts of Interest}

The authors declare that there are no conflicts of interest.

\section{Authors' Contributions}

All authors contributed to the design of this study. All authors reviewed and revised the draft further and approved the final version for submission.

\section{Acknowledgments}

We would like to say thanks to the University of Campania "Luigi Vanvitelli" and "Pamukkale University" for giving the opportunity for doing this thesis and for their financial support. Last but not the least, we would like to thank our study participants.

\section{References}

[1] X. Wang, Y. Zeng, X. Huang, and Y. Zhang, "Prevalence and genotype distribution of human papillomavirus in invasive cervical cancer, cervical intraepithelial neoplasia, and asymptomatic women in Southeast China," BioMed Research International, vol. 2018, Article ID 2897937, 10 pages, 2018.

[2] A. Handisurya, C. Schellenbacher, and R. Kirnbauer, "Erkrankungen durch humane Papillomviren (HPV)," Journal der Deutschen Dermatologischen Gesellschaft, vol. 7, no. 5, pp. 453-467, 2009.

[3] H. zur Hausen, "Papillomaviruses and cancer: from basic studies to clinical application," Nature Reviews Cancer, vol. 2, no. 5, pp. 342-350, 2002.

[4] S. Duensing and K. Münger, "Mechanisms of genomic instability in human cancer: insights from studies with human papillomavirus oncoproteins," International Journal of Cancer, vol. 109, no. 2, pp. 157-162, 2004.

[5] World Health Organization, Human Papillomavirus (HPV) and Cervical Cancer, World Health Organization, Geneva, Switzerland, 2015.

[6] A. Kent, "HPV vaccination and testing," Reviews in Obstetrics \& Gynecology, vol. 3, no. 1, pp. 33-34, 2010.

[7] G. Prue, P. Baker, D. Graham, C. Nutting, P. Greenhouse, and M. Lawler, "It is time for universal HPV vaccination," The Lancet, vol. 392, no. 10151, pp. 913-914, 2018. 
[8] S. Sheikh, E. Biundo, S. Courcier et al., "A report on the status of vaccination in Europe," Vaccine, vol. 36, no. 33, pp. 4979-4992, 2018.

[9] J. M. L. Brotherton, A. R. Giuliano, L. E. Markowitz, E. F. Dunne, and G. S. Ogilvie, "Monitoring the impact of HPV vaccine in males-Considerations and challenges," Papillomavirus Research, vol. 2, pp. 106-111, 2016.

[10] P. Basu, C. Bhattacharya, J. Biswas, P. Singh, and D. Banerjee, "Efficacy and safety of human papillomavirus vaccine for primary prevention of cervical cancer: a review of evidence from phase III trials and national programs," South Asian Journal of Cancer, vol. 2, no. 4, pp. 187-192, 2013.

[11] Intesa tra il Governo, le Regioni e le Province autonome di Trento e Bolzano sul documento recante "Piano Nazionale Prevenzione Vaccinale (PNPV) 2012-2014". Intesa ai sensi dell'articolo 8, comma 6, della legge 5 giugno 2003, n. 131.

[12] A. Petrelli, P. Giorgi Rossi, L. Francovich et al., "Geographical and socioeconomic differences in uptake of Pap test and mammography in Italy: results from the National Health Interview Survey," BMJ Open, vol. 8, no. 9, article e021653, 2018.

[13] C. Giambi, Stato di Avanzamento della Campagna Vaccinale per l'HPV: Dati di Copertura Vaccinale al 31/12/2011, Istituto Superiore di Sanitá, Rome, Italy, 2011, https://www.epicentro.iss. it/hpv/pdf/Aggiornamento_datiHPV_31_12_2011_validato.pdf.

[14] B. Adamo and A. Simonetti, Andamento della campagna vaccinale contro l'Hpv nella Asl di Napoli, Azienda Sanitaria Locale: Napoli 1 Centro Servizio Epidemiologia e Prevenzione, Naples, Italy, 2011, https:/www.epicentro.iss.it/ territorio/campania/pdf/HPV_Napoli1_301012.pdf.

[15] H. G. Sahin, A. Kolusari, and H. Guducuoglu, "Prevalence of high risk human papillomavirus (HPV) infection and abnormal cervical cytology and knowledge about HPV vaccine in Eastern Turkey," European Journal of Gynaecological Oncology, vol. 38, no. 2, pp. 241-244, 2017.

[16] T. C. Saglik and Bakanligi Türkiye Halk Sagligi Kurumu Kanserle Savas Dairesi Baskanligi, Serviks Kanseri Taramasi Ulusal Standartlari (National Standards of Cervical Cancer Screening), Bakanligi Türkiye Halk Sagligi Kurumu Kanserle Savas Dairesi Baskanligi, Ankara, Turkey, 2007, in Turkish, http://kanser.gov.tr/Dosya/tarama/serviks.pdf.

[17] S. Gupta, C. Palmer, E. M. Bik et al., "Self-sampling for human papillomavirus testing: increased cervical cancer screening participation and incorporation in international screening programs,” Front Public Health, vol. 6, p. 77, 2018.

[18] A. Vorsters, M. Arbyn, M. Baay et al., "Overcoming barriers in HPV vaccination and screening programs," Papillomavirus Research, vol. 4, pp. 45-53, 2017.

[19] E. Von Elm, D. G. Altman, M. Egger et al., "The strengthening the reporting of observational studies in epidemiology (STROBE) statement: guidelines for reporting observational studies," The Lancet, vol. 370, no. 9596, pp. 1453-1457, 2007.

[20] J. H. Smith, "Bethesda 2001," Cytopathology, vol. 13, no. 1, pp. 4-10, 2002.

[21] P. Brianti, E. De Flammineis, and S. R. Mercuri, "Review of HPV-related diseases and cancers," New Microbiologica, vol. 40, no. 2, pp. 80-85, 2017.

[22] D. M. Harper and L. R. DeMars, "HPV vaccines-a review of the first decade," Gynecologic Oncology, vol. 146, no. 1, pp. 196-204, 2017.

[23] M. R. Campitiello, P. De Franciscis, D. Mele et al., "Endometrial LGR7 expression during menstrual cycle," Fertility and Sterility, vol. 95, no. 8, pp. 2511-2514, 2011.
[24] A. S. Laganà, V. Gavagni, J. V. Musubao, and A. Pizzo, “The prevalence of sexually transmitted infections among migrant female patients in Italy," International Journal of Gynecology \& Obstetrics, vol. 128, no. 2, pp. 165-168, 2015.

[25] W. Winkelstein Jr., "Smoking and cancer of the uterine cervix: hypothesis," American Journal of Epidemiology, vol. 106, no. 4, pp. 257-259, 1977.

[26] R. A. Siciliano, M. F. Mazzeo, V. Spada et al., "Rapid peptidomic profiling of peritoneal fluid by MALDI-TOF mass spectrometry for the identification of biomarkers of endometriosis," Gynecological Endocrinology, vol. 30, no. 12, pp. 872-876, 2014.

[27] J. S. Smith, C. Bosetti, N. Muñoz et al., "Chlamydia trachomatisand invasive cervical cancer: a pooled analysis of the IARC multicentric case-control study," International Journal of Cancer, vol. 111, no. 3, pp. 431-439, 2004.

[28] M. Torella, P. De Franciscis, C. Russo et al., "Stress urinary incontinence: usefulness of perineal ultrasound," La Radiologia Medica, vol. 119, no. 3, pp. 189-194, 2014.

[29] D. H. Watts, M. Fazarri, H. Minkoff et al., "Effects of bacterial vaginosis and other genital infections on the natural history of human papillomavirus infection in HIV-1Infected and high-risk HIV-1-Uninfected women," The Journal of Infectious Diseases, vol. 191, no. 7, pp. 1129-1139, 2005.

[30] P. De Franciscis, L. Cobellis, F. Fornaro, E. Sepe, M. Torella, and N. Colacurci, "Low-dose hormone therapy in the perimenopause," International Journal of Gynecology \& Obstetrics, vol. 98, no. 2, pp. 138-142, 2007.

[31] M. T. Schettino, F. P. Ammaturo, D. Labriola, P. De Franciscis, N. Colacurci, and M. Torella, "Betulinic acid and possible influence on the clearance of Human Papilloma Virus: cytological and virological followup," Minerva Ginecologica, vol. 65, no. 6, pp. 661-668, 2013.

[32] W. Zhao, M. Hao, Y. Wang et al., "Association between folate status and cervical intraepithelial neoplasia," European Journal of Clinical Nutrition, vol. 70, no. 7, pp. 837-842, 2016.

[33] M. T. Schettino, F. P. Ammaturo, E. Grimaldi et al., "Persistent papillomavirus type- 31 and type- 45 infections predict the progression to squamous intraepithelial lesion," Taiwanese Journal of Obstetrics and Gynecology, vol. 53, no. 4, pp. 494-497, 2014.

[34] A. Simonelli, R. Guadagni, P. De Franciscis et al., "Environmental and occupational exposure to bisphenol $\mathrm{A}$ and endometriosis: urinary and peritoneal fluid concentration levels," International Archives of Occupational and Environmental Health, vol. 90, no. 1, pp. 49-61, 2017.

[35] L. Guo, H. Zhu, C. Lin et al., "Associations between antioxidant vitamins and the risk of invasive cervical cancer in Chinese women: a case-control study," Scientific Reports, vol. 5, no. 1, p. 13607, 2015.

[36] M. T. Schettino, G. Mainini, F. P. Ammaturo et al., "The role of human papillomavirus in cervical preneoplastic lesions: the relationship between virus genotype and persistence or clearance of the infection," European Journal of Gynaecological Oncology, vol. 39, no. 4, pp. 564-568, 2018.

[37] S. Ozyer, O. Uzunlar, S. Ozler et al., “Awareness of Turkish female adolescents and young women about HPV and their attitudes towards HPV vaccination," Asian Pacific Journal of Cancer Prevention, vol. 14, no. 8, pp. 4877-4881, 2013. 
[38] C. Baykal, A. Al, M. G. Uğur, N. Cetinkaya, R. Attar, and P. Arioglu, "Knowledge and interest of Turkish women about cervical cancer and HPV vaccine," European Journal of Gynaecological Oncology, vol. 29, no. 1, pp. 76-79, 2008.

[39] Ministero della Salute della Repubblica Italiana (CNESPS, ISS), EpiCentro Dati, Coperture Vaccinali al 31/12/2017 per HPV, epicentro.iss.it, Ministero della Salute della Repubblica Italiana, Rome, Italy, http://www.salute.gov.it/imgs/C_17_tavole_27_ allegati_iitemAllegati_0_fileAllegati_itemFile_1_file.pdf.

[40] F. Napolitano, M. Navaro, L. Vezzosi, G. Santagati, and I. F. Angelillo, "Primary care pediatricians' attitudes and practice towards HPV vaccination: a nationwide survey in Italy," PLoS One, vol. 13, no. 3, Article ID e0194920, 2018.

[41] I. Baussano, F. Lazzarato, G. Ronco, and S. Franceschi, "Impacts of human papillomavirus vaccination for different populations: a modeling study," International Journal of Cancer, vol. 143, no. 5, pp. 1086-1092, 2018.

[42] S. Igidbashian, M. T. Schettino, S. Boveri et al., "Tissue genotyping of 37 in situ and invasive cervical cancer with a concomitant negative HC2 HPV DNA test," Journal of Lower Genital Tract Disease, vol. 18, no. 1, pp. 87-91, 2014.

[43] P. Dursun, S. S. Senger, H. Arslan, E. Kuşçu, and A. Ayhan, "Human papillomavirus (HPV) prevalence and types among Turkish women at a gynecology outpatient unit," BMC Infectious Diseases, vol. 9, no. 1, p. 191, 2009.

[44] P. Dursun, A. Ayhan, L. Mutlu et al., "HPV types in Turkey: multicenter hospital based evaluation of 6388 patients in Turkish gynecologic oncology group centers," Turkish Journal of Pathology, vol. 29, no. 3, pp. 210-216, 2013. 


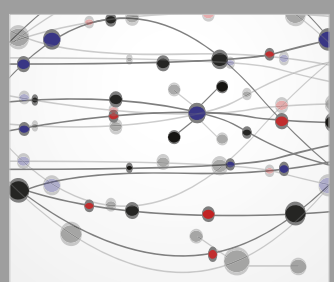

The Scientific World Journal
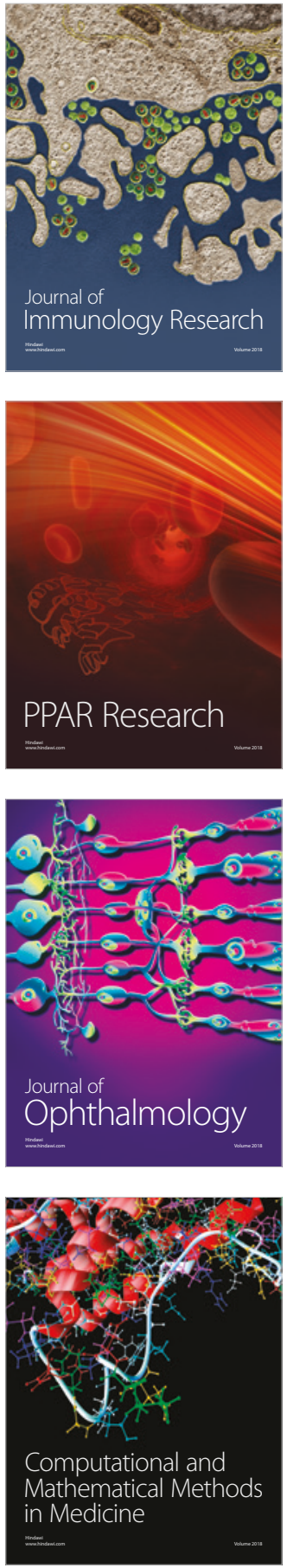

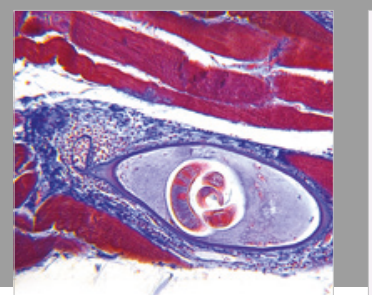

Gastroenterology Research and Practice

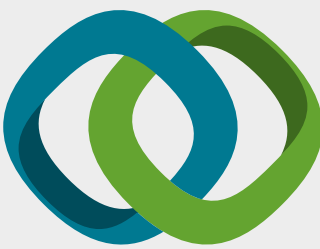

\section{Hindawi}

Submit your manuscripts at

www.hindawi.com
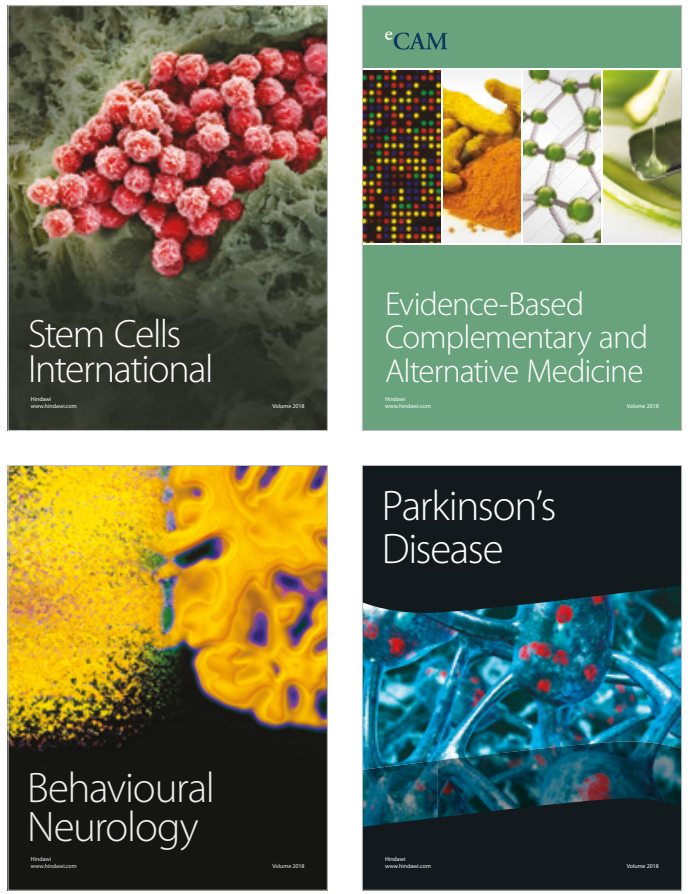

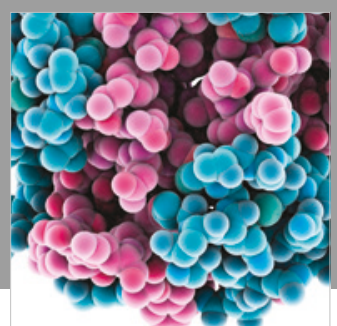

ournal of

Diabetes Research

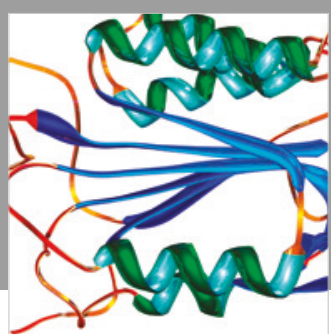

Disease Markers
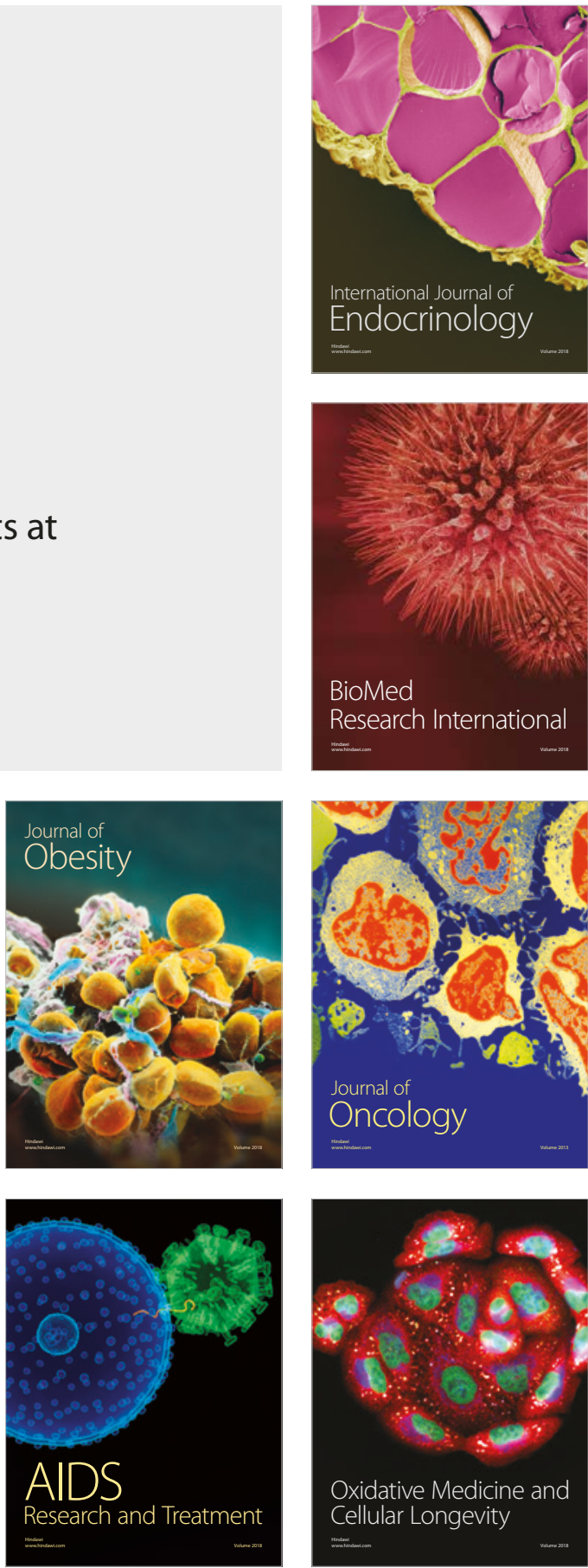